\title{
Three-dimensional strain analysis of asphalt pavement based on vehicle-pavement model of interaction
}

\author{
Runfeng Zhang ${ }^{1} \mathbb{D} \cdot$ Xiaolan Liu $^{2} \cdot$ Xianmin Zhang $^{1,3}$
}

Received: 27 April 2021 / Accepted: 15 September 2021

Published online: 28 September 2021

(c) The Author(s) 2021 OPEN

\begin{abstract}
This study analyzes the 3D (3D) strain on a pavement by using a model of a vehicle with seven degrees of freedom and that of a road in elastic half-space by using the finite element software ANSYS. The results are as follows: The 3D strain on the two wheels along the centerline was significantly influenced by the superposition of the wheel, and the 3D strain under a single wheel was far higher than that along the centerline of two wheels, and represented the most unfavorable position on the road. The vertical strain consisted mainly of compressive strain at different depths, and that at the bottom of the pavement was slightly higher than that on top. The longitudinal and transverse strains were all compressive strains on top of the pavement and tensile strains at the bottom, respectively. The longitudinal and transverse strains both on top and at the bottom of the pavement were similar. The authors then analyzed the influence of the thickness of the pavement, its modulus, and equivalent resilient modulus on the vertical compressive strain, longitudinal tensile strain, and transverse tensile strain in case of a single wheel. Furthermore, a model to predict the 3D strain under the comprehensive effect of the structural parameters of the road was established. It can provide the basis and a reference for the design, construction, fault detection, and maintenance of roads.
\end{abstract}

Keywords Asphalt pavement $\cdot 3 \mathrm{D}$ strain $\cdot$ Vertical strain $\cdot$ Longitudinal strain $\cdot$ Transverse strain

\section{Introduction}

Both the American pavement design code [1] and Chinese specifications for the design of the asphalt pavements on highways (JTG D50-2017) [2] use the strain at the bottom of the pavement at the centerline of two wheels as an important index to evaluate the fatigue-induced failure of the asphalt pavements.

Three methods are mainly used in the literature to examine the strain at the bottom of the surface layer: theoretical analysis, indoor and outdoor tests, and numerical simulations. Theoretical analysis can be used to solve for the strain through system dynamics theory by dividing the pavement into a multi-layer elastic or viscoelastic system, and expressing the dynamic load of the vehicle by using a spatial distribution function or a change function over time. The dynamic response of the road is typically not analyzed by using such a method owing to the complex theory and calculation involved [3-5]. Indoor and outdoor tests generally include accelerated indoor loading tests and outdoor field tests. The former cannot be carried out efficiently and over a long distance due to limitations on the mode of driving and the length of the equipment $[6$, 7]. Outdoor field tests are difficult to use to study a variety

Runfeng Zhang, cauczrf@126.com | 'School of Transportation Science and Engineering, Civil Aviation University of China, Tianjin 300300, People's Republic of China. ${ }^{2}$ School of Civil Engineering, Tianjin Chengjian University, Tianjin 300384,

People's Republic of China. ${ }^{3}$ College of Civil Aviation, Nanjing University of Aeronautics and Astronautics, Nanjing 210016, People's Republic of China. 
of structural combinations of the asphalt pavements due to their disadvantages of high cost and a long cycle [8, 9]. Numerical simulations can be used to represent the dynamic response of the asphalt pavement under different dynamic loads of the vehicle by assigning different properties to the materials of each structural layer of the pavement, and by combining the settings of the boundary constraints and the load conditions. They are widely used, and are less complex than theoretical analysis, and shorter and cheaper than indoor and outdoor tests [10-12].

Wang and Al-Qadi [13] established coupling response models of wide-base tires and dual-tire assemblies on asphalt pavements, respectively. They found that the maximum longitudinal tensile strain at the bottom of the pavement due to the by wide-base tire was higher than that due to dual-tire assemblies, but the maximum transverse strain at its bottom due to the former was smaller than that due to the latter. Ozer [14] analyzed the influence of the boundary conditions on strain at the bottom of an asphalt pavement based on a 3D finite element model. Chen et al. [15] analyzed the responses of thick and thin asphalt pavements to the longitudinal and the vertical strains at the bottom of the surface layer through a numerical model. Wang and Li [16] compared the longitudinal and transverse strains at the bottom of a layer of the asphalt pavement under the action of loads due to FWD and a moving vehicle through a numerical model, and concluded that there were differences in the strainrelated response under the two types of loads. The FWD load could not fully simulate the load due to the moving vehicle. Based on a 3D numerical model of an asphalt pavement under a moving load, Dong et al. [17] studied the law of variation in 3D strain at the bottom of an asphalt pavement using vehicle traveling at different speeds, different positions of lateral action of the load, and varying acceleration and deceleration of the vehicle. Chen et al. [18] established a response model of an asphalt pavement under multi-wheel, random, dynamic load of vehicles, and analyzed the laws of response of the vertical, longitudinal, and transverse strains at the bottom of the asphalt pavement when the front and rear axles of the vehicle passed over it in succession. Pan et al. [19] analyzed the influence of different temperatures and axial loads on strain at the bottom of an asphalt pavement through a numerical model, and established a model to predict it. Their results showed that the error between the predictions of the model and field measurements was not more than $10 \%$. Lu et al. [20] explored the influence of the loading time and temperature of the pavement on strain at the bottom of an asphalt pavement through a dynamic response model of the pavement under half-sine load. Wang [21] analyzed the effect of dynamic loading on flexible responses of the pavement at different vehicle speeds and pavement roughnesses by using an integrated approach to vehicle-tire-pavement interaction. The results indicated that a rougher pavement surface can yield higher responses of the pavement and accelerate its failure at locations where large dynamic loads are induced. Zhao [22] analyzed the dynamic responses of the asphalt pavements induced by random loads under the wheels of a moving truck owing to surface roughness, and found that the surface roughness of the pavement significantly affected the variation in the dynamic load and responses of the pavement at different locations. Recent studies have shown that the modulus of the material of the pavement has a significant effect on its dynamic response $[23,24]$.

Previous studies in the area that have used numerical models have focused on the influence of strain at the bottom of the asphalt pavement by using the parameters of the load due to the vehicle (such as axle load, speed, location, action time, and tire type), temperature, boundary conditions, and thickness of the asphalt pavement. The law of influence of parameters of the structure of the asphalt pavement (such as its modulus and thickness, and equivalent resilient modulus of the top of the base) on strain at its bottom has not been systematically and comprehensively analyzed. The model for predicting strain at the bottom of the pavement has thus not been established. In addition, current specifications do not compare strain at the bottom on the centerline of two wheels with that of a single wheel to identify the most unfavorable position of strain at the bottom of the pavement.

This study establishes a model of a vehicle with seven degrees of freedom and one of a road in elastic, layered half-space. A vehicle-road coupling response model is used to analyze the influence of the modulus of the pavement, its thickness, and the equivalent resilient modulus of the top of the base on the 3D strain (vertical, longitudinal, and transverse strains) at the bottom of the asphalt pavement. We identify the most unfavorable position of strain at the bottom of the pavement as well. We used a numerical model of 252 sets of combinations of the structure of the asphalt pavement to establish a 3D model to predict strain. This model can provide a reference and a basis for the design and detection of fatigue-induced damage to asphalt pavements.

\section{Establishing and verifying vehicle-road coupling model}

\subsection{Field test}

Three pavement structures of the Tongdan Expressway, located in Tonghua County in China, were selected as the test section [25]. The first structure was an asphalt 
Table 1 Structural parameters of layers of the asphalt pavement in the field test

\begin{tabular}{llll}
\hline Road number & & Pavement & Subgrade \\
\hline Structure 1 & Modulus (MPa) & 1400 & 962.6 \\
& Thickness (m) & 0.32 & - \\
Structure 2 & Modulus (MPa) & 1400 & 744.60 \\
& Thickness (m) & 0.26 & - \\
Structure 3 & Modulus (MPa) & 1400 & 941.80 \\
& Thickness (m) & 0.27 & -
\end{tabular}

pavement with a graded gravel layer, cement-stabilizing sand layer, and a gravel cushion. The second structure was an asphalt pavement with a graded layer of crushed stone and a gravel cushion, and the third structure was an asphalt pavement with a graded layer of crushed stone and a cement-stabilizing layer. The parameters of each layer of the road structure were inversed from data measured by a falling-weight deflectometer, as shown in Table 1.

Strain sensors were embedded at the bottom of the asphalt pavement of each road structure to measure the maximum strain induced by a six-axle truck (axle loads: 1990 kg, 1840 kg, 5910 kg, 4530 kg, 4510 kg, 4830 kg) passing through the test section at the speed of $28 \mathrm{~km} / \mathrm{h}$.

\subsection{Verifying vehicle-road coupling model through field test}

Finite element models were established using the finite element software ANSYS to simulate the strain-induced response under the above conditions. The vehicle load was a dynamic load that was affected by the roughness of the road [26]. Therefore, a model of the vehicle with seven degrees of freedom that considered road roughness was established [27]. In the model, the body of the car used the MPC184 rigid beam element, which does not consider elastic deformation of the elements. Each element has two nodes, each of which has six degrees of freedom: three translational and three rotational. The Mass 21 element was used to simulate the suspension of the vehicle and its non-suspension mass as well as the pitching and tilting moments of inertia. The spring and damping elements of the vehicle were simulated by the Combine14 element, and its dynamic load was solved by using the complete method in structural transient analysis.

Considering the range of influence of vehicle load and the accuracy of calculations, the dimensions of the subgrade were set to $23 \mathrm{~m}$ ( $X$ direction), $16 \mathrm{~m}$ ( $Z$ direction), and $9 \mathrm{~m}$ ( $Y$ direction) in terms of length, width, and depth, respectively, in the finite element model $[28,29]$. The bottom of the model was set to be completely fixed, and the
$X$ and $Z$ directions constrained only displacement. One of the structural models of the pavement is shown in Fig. 1.

A comparison between the calculated maximum strain of the three pavement structures under the above vehicle load and the field test values is shown in Table 2 .

Table 2 shows that the error between the calculated value of the strain model and the measured value through the field test was within $10 \%$. The larger error in structure 1 might have been related to the accuracy of the measured value, but the model generally met the application-related requirements of road engineering.

\section{Three-dimensional strain response}

To study the 3D strain response of the asphalt pavement under different dynamic loads of the vehicle, the structural model of the pavement was established as shown in Fig. 1. The dimensions and boundary conditions of the model were the same as described in Sect. 2.2. The sampling points were selected according to the centerline of the two wheels and the depth of the response to vehicle load (as shown in Fig. 2). The specific sampling points were arranged as follows: The centerline of the two wheels, the center of the track line of the wheel, the top of the pavement, and its bottom were $0.4 \mathrm{~m}$ and $1 \mathrm{~m}$ from the subgrade in the direction of road depth. To simulate the process of pavement detection, we used a model where a 30 $t$ vehicle moved along the centerline of the pavement at a speed of $20 \mathrm{~m} / \mathrm{s}$. The roughness of the pavement was level $\mathrm{B}$ based on the relevant specifications in China regarding pavement inspection.

The relevant parameters of the vehicle model are shown in Table 3.

The parameters of the structural layer were obtained from Chinese specifications for the design of asphalt pavements of highways, and the properties of the pavement are shown in Tables 4 and 5.

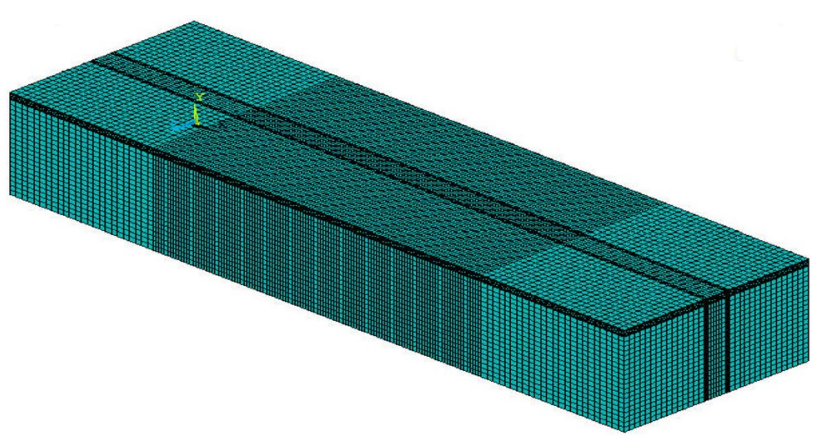

Fig. 1 Model of pavement structure 
Table 2 The maximum strain in the field test

\begin{tabular}{llccc}
\hline Road number & & Structure 1 & Structure 2 & Structure 3 \\
\hline Longitudinal strain $(\mu \varepsilon)$ & Field test $(\mu \varepsilon)$ & 48.50 & 85.90 & 69.70 \\
& Calculated $(\mu \varepsilon)$ & 52.41 & 87.87 & 71.07 \\
& Error $(\%)$ & 8.06 & 2.29 & 1.37 \\
Transverse strain $(\mu \varepsilon)$ & Field test $(\mu \varepsilon)$ & 36.00 & 90.70 & 55.80 \\
& Calculated $(\mu \varepsilon)$ & 39.17 & 87.51 & 59.32 \\
& Error $(\%)$ & 8.81 & 3.52 & 0.86 \\
\hline
\end{tabular}

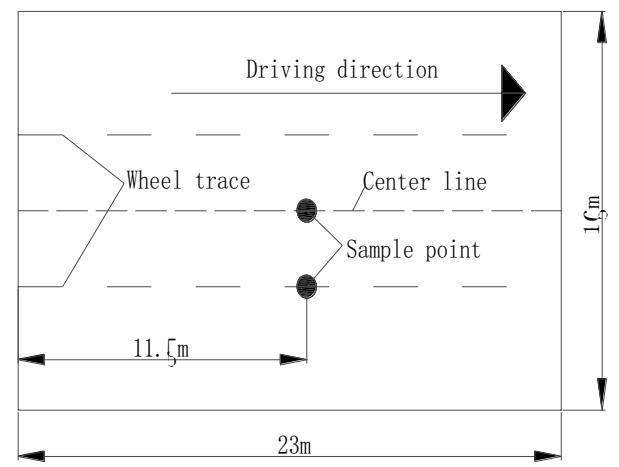

(a)

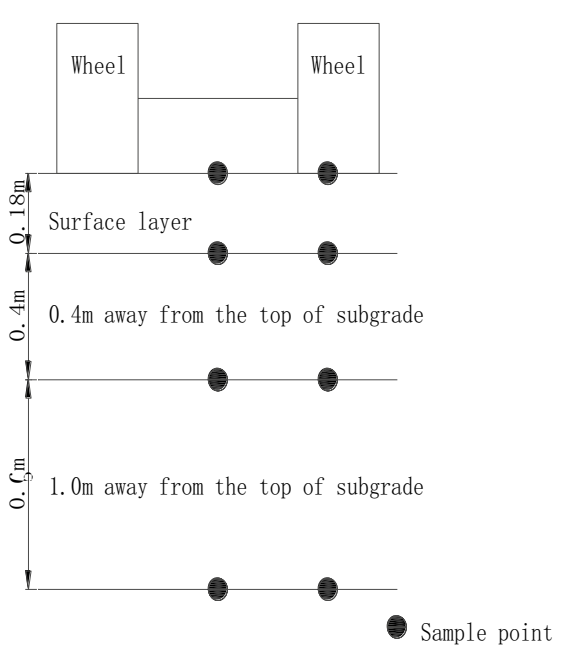

(b)

Fig. 2 Layout of sampling points layout of $\mathbf{a}$ planar graph and $\mathbf{b}$ cross-sectional drawing

To further verify the correctness of the model, a numerical model was built to compare with it based on the Boussinesq theory [30]. In the model, a circular uniform load with a radius of $0.3 \mathrm{~m}$ and tire pressure of $0.7 \mathrm{MPa}$ was applied to the road structure to solve for stress at different depths. The results of the numerical model and the Boussinesq theory are compared in Table 6.
Table 6 shows that the error between the numerical obtained stress and the theoretical value was smaller than $5 \%$. This verified the correctness of the model, and indicated that it could adequately reflect the mechanical response of the road structure.

\subsection{Response law of vertical strain}

Figure 3 presents the laws of response of the vertical strain along the depth of the centerline of the two wheels and in case of a single wheel. The tensile strain was positive and the compressive strain was negative.

As shown in Fig. 3a, the vertical strain of the centerline of the two wheels consisted of alternately changing tensile and compressive strains at different depths of the road. The vertical strains on the top and bottom of the pavement had similar values, but with the opposite signs, and the vertical strain decreased with an increase in the distance from the subgrade. The vertical strain $0.4 \mathrm{~m}$ from the top of base layer was the highest because this location ( $0.4 \mathrm{~m}$ from the top of the base layer) was at the top of the subgrade, where the modulus of the structural layer of the pavement was larger than that of the subgrade, and the effect of superposition of the wheels was remarkable.

Figure $3 \mathrm{~b}$ shows that the vertical strain of the centerline of the two wheels consisted of tensile and compressive strains that changed alternately at different depths of the road. The values of compressive strain were significantly higher than that of the tensile strain. The alternation of tensile and compressive strains on top of the pavement and $0.4 \mathrm{~m}$ away from the top of the subgrade were significant. The vertical strain at the bottom of the pavement was mainly compressive strain, and the vertical strain $1 \mathrm{~m}$ away from the subgrade was much lower than those at other locations.

A comparison of Fig. $3 a$, $b$ shows that the vertical strain under a single wheel was about two to five times that at the centerline of the two wheels. The vertical strain at the centerline of the two wheels was significantly affected by the superposition effect of the wheel. When the front 
Table 3 Parameters of the test vehicle model

\begin{tabular}{ll}
\hline Measurement & Parameter \\
\hline Overall mass $(\mathrm{kg})$ & $\mathrm{M}_{0}=30,000$ \\
Mass of suspension system $(\mathrm{kg})$ & $\mathrm{m}_{\mathrm{CZ}}=27,000$ \\
Mass of front axle $(\mathrm{kg})$ & $\mathrm{m}_{\mathrm{QZ}}=600$ \\
Mass of rear axle $(\mathrm{kg})$ & $\mathrm{m}_{\mathrm{Hz}}=2,400$ \\
Mass moment of inertia $\left(\mathrm{kg} \cdot \mathrm{m}^{2}\right)$ & $\mathrm{J}_{\mathrm{x}}=1.0 \times 10^{6}, \mathrm{~J}_{\mathrm{y}}=3.6 \times 10^{5}$ \\
Suspension stiffness $(\mathrm{N} / \mathrm{m})$ & $\mathrm{K}_{\mathrm{xQZ}}=0.8 \times 10^{6}, \mathrm{~K}_{\mathrm{xHz}}=2.0 \times 10^{6}$ \\
Tire stiffness $(\mathrm{N} / \mathrm{m})$ & $\mathrm{K}_{\mathrm{LQZ}}=1.2 \times 10^{6}, \mathrm{~K}_{\mathrm{LHz}}=4.8 \times 10^{6}$ \\
Suspension damping $(\mathrm{N} \cdot \mathrm{s} / \mathrm{m})$ & $\mathrm{C}_{\mathrm{xQZ}}=5.0 \times 10^{3}, \mathrm{C}_{\mathrm{xHZ}}=2.0 \times 10^{4}$ \\
Tire damping $(\mathrm{N} \cdot \mathrm{s} / \mathrm{m})$ & $\mathrm{C}_{\mathrm{LQZ}}=6.0 \times 10^{3}, \mathrm{C}_{\mathrm{LHZ}}=2.4 \times 10^{4}$ \\
Dimensions to determine mass center $(\mathrm{m})$ & $\mathrm{L}_{\mathrm{HZ}}=0.9, \mathrm{~L}_{\mathrm{QZ}}=3.6, \mathrm{~L}_{\mathrm{y}}=0.9$ \\
\hline
\end{tabular}

Table 4 Parameters of the structural layer

\begin{tabular}{lllll}
\hline $\begin{array}{l}\text { Structural } \\
\text { layer }\end{array}$ & $\begin{array}{l}\text { Thickness } \\
(\mathrm{m})\end{array}$ & $\begin{array}{l}\text { Modulus } \\
(\mathrm{MPa})\end{array}$ & $\begin{array}{l}\text { Poisson's } \\
\text { ratio }\end{array}$ & $\begin{array}{l}\text { Density }(\mathrm{kg} / \\
\left.\mathrm{m}^{3}\right)\end{array}$ \\
\hline $\begin{array}{l}\text { Pavement } \\
\text { Under the } \\
\text { pavement }\end{array}$ & 0.18 & 2000 & 0.25 & 2400 \\
\hline
\end{tabular}

and rear axles of the vehicle passed through the sampling point, respectively, the vertical strain changed by little. The vertical strain under a single wheel was less affected by the superposition effect of the wheel, and changed

Table 6 Correlation between numerical and theoretical solutions

\begin{tabular}{lccc}
\hline $\begin{array}{l}\text { Distance from the } \\
\text { subgrade }(\mathrm{m})\end{array}$ & $\begin{array}{l}\text { Numerical solu- } \\
\text { tion }(\mathrm{kPa})\end{array}$ & $\begin{array}{l}\text { Theoretical solu- } \\
\text { tion }(\mathrm{kPa})\end{array}$ & Error $(\%)$ \\
\hline 0.3 & -473.93 & -452.51 & 4.73 \\
0.9 & -105.73 & -102.33 & 3.32 \\
1.5 & -41.34 & -39.99 & 3.37 \\
2.1 & -21.10 & -20.89 & 0.98 \\
2.7 & -12.81 & -12.77 & 0.35 \\
3 & -10.43 & -10.37 & 0.58 \\
3.3 & -8.63 & -8.59 & 0.48 \\
\hline
\end{tabular}

significantly when the front and rear axles of the vehicle passed the sampling point.

\subsection{Response law of longitudinal strain}

Figure 4 shows the laws of response of longitudinal strain along the depth under the centerline of the two wheels and under a single wheel. The tensile strain was positive and the compressive strain negative.

Figure 4a shows that the response of longitudinal strain along the driving direction was more significant than that of the vertical strain when the depth of the road structure was constant. The longitudinal strain of the pavement was mainly compressive strain when the front and rear axles of the vehicle passed through the sampling point. The longitudinal strain at the bottom of the pavement varied alternately over a small range of tension and compression, and was mainly tensile strain. It was also tensile strain at $0.4 \mathrm{~m}$ and $1 \mathrm{~m}$ from the subgrade.

Figure $4 \mathrm{~b}$ shows that the longitudinal strain under a single wheel was mainly compressive strain on top of the pavement. It also shows tensile strain at the bottom of the pavement, and $0.4 \mathrm{~m}$ and $1 \mathrm{~m}$ from the subgrade. When the front and rear axles of the vehicle passed through the sampling point, the compressive strain on top of the pavement was close to the tensile strain at the bottom of the pavement. The longitudinal strain decreased gradually
Table 5 Properties of the pavement structure

\begin{tabular}{llllll}
\hline Layer & Material & Thickness $(\mathrm{m})$ & Modulus (MPa) & Poisson's Ratio & $\begin{array}{l}\text { Unit } \\
\text { weight } \\
\left(\mathrm{kg} / \mathrm{m}^{3}\right)\end{array}$ \\
\hline Surface layer & Asphalt concrete & 0.18 & 6000 & 0.25 & 2400 \\
Base layer & Cement-stabilized macadam & 0.40 & 34000 & 0.35 & 2200 \\
\hline
\end{tabular}






(a)

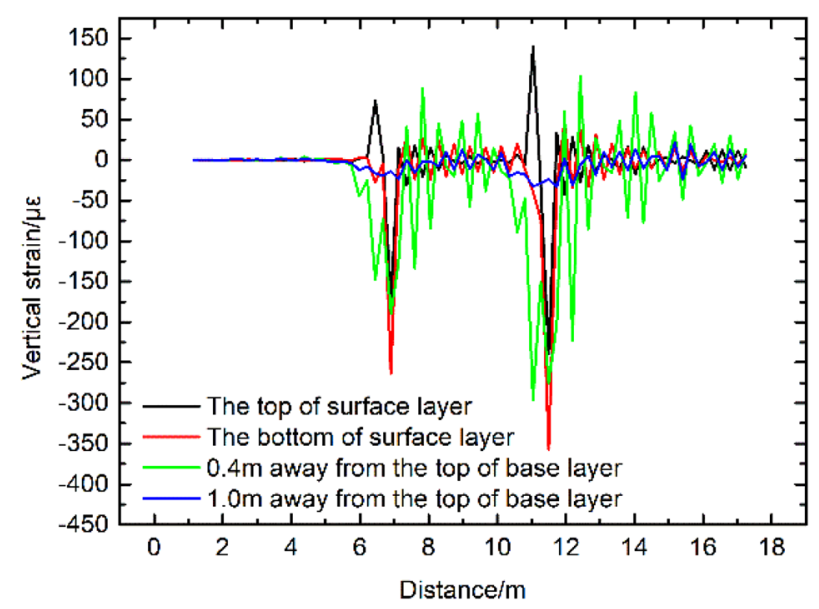

(b)

Fig. 3 Vertical strain of $\mathbf{a}$ the centerline of the two wheels and $\mathbf{b}$ a single wheel

with an increase in the distance from the subgrade. When this distance was $1 \mathrm{~m}$, the longitudinal strain tended to be stable.

A comparison of Fig. $4 a$, $b$ shows that the longitudinal strain directly below a single wheel was about three to five times that at the centerline of the two wheels. The longitudinal strain at the centerline of the two wheels was significantly affected by the superposition effect of the wheel. And when the front and rear axles passed through the sampling point, there was little difference in the longitudinal strain. However, the longitudinal strain directly under a single wheel was less affected by the superposition effect of the wheel, and differences in it were clear when the front and rear axles passed through the sampling point, respectively.

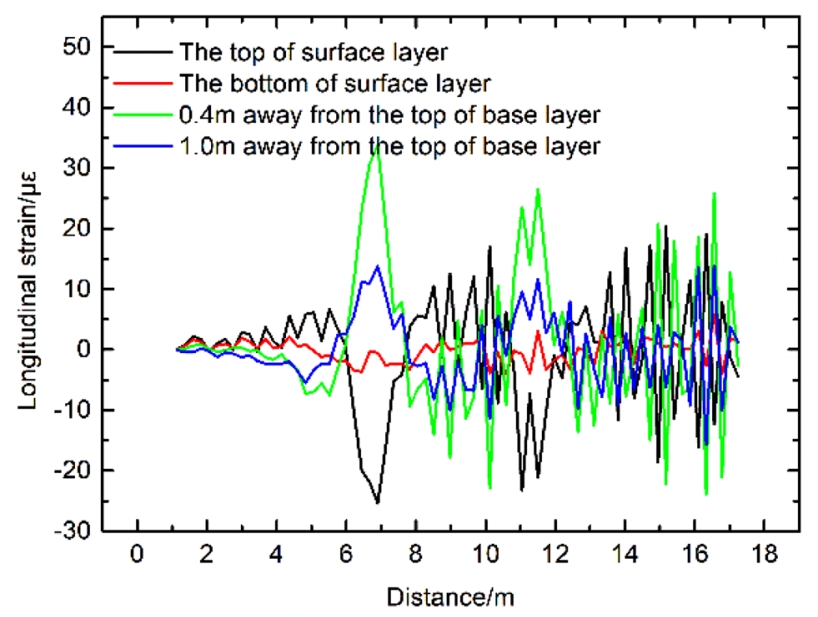

(a)

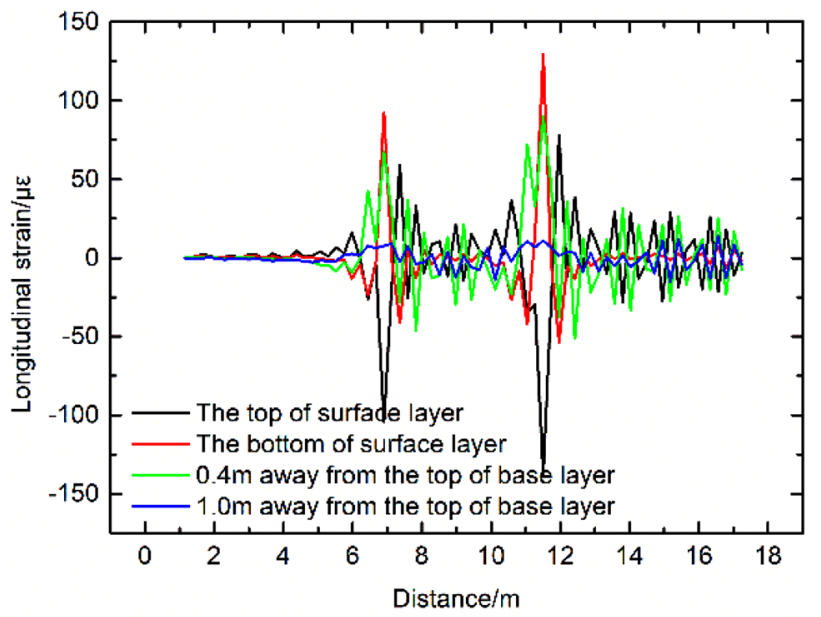

(b)

Fig. 4 Longitudinal strains of a the centerline of the two wheels and $\mathbf{b}$ under a single wheel

\subsection{Response law of transverse strain}

Figure 5 shows the law of responses of the transverse strain along the depth of the centerline of two wheels and under a single wheel, respectively. The tensile strain was positive and the compressive strain negative.

Figure 5a shows that when the front and rear axles of the vehicle passed through the sampling point, respectively, the transverse strain on top of the pavement was mainly tensile strain, and was mainly compressive strain at the bottom of the pavement, and $0.4 \mathrm{~m}$ and $1 \mathrm{~m}$ from the subgrade. The transverse strain occurred only between -12 and $14 \mu \varepsilon 1 \mathrm{~m}$ from the subgrade. At the same time, the transverse strain decreased with an increase in depth away from the subgrade. 


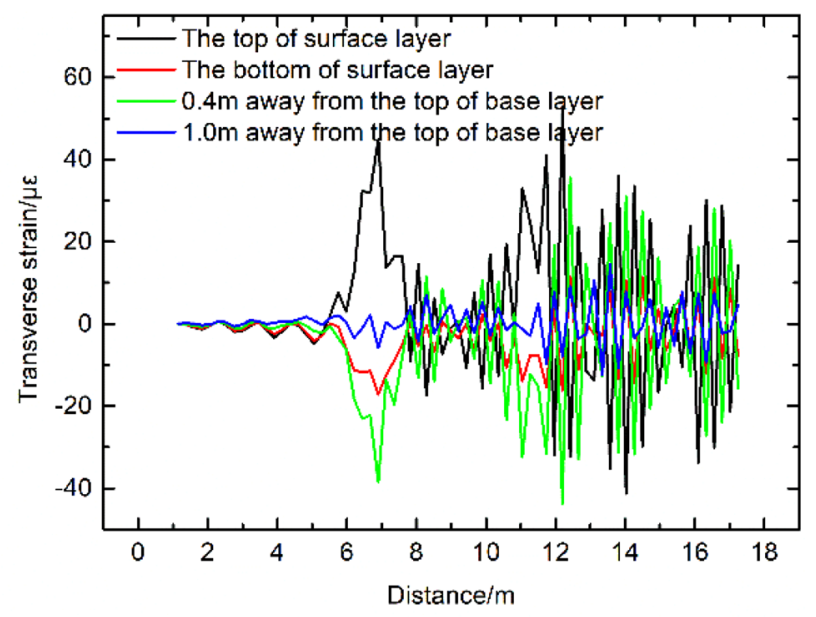

(a)

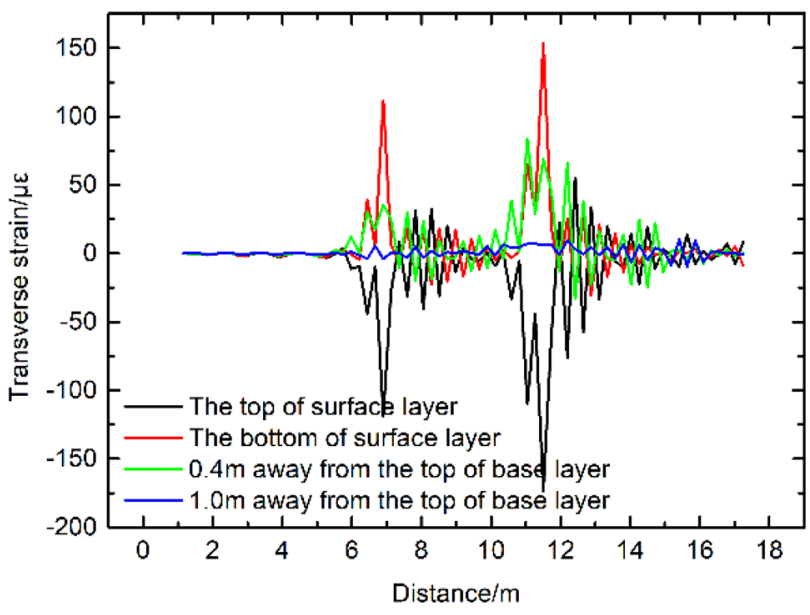

(b)

Fig. 5 Transverse strains at a the centerline of the two wheels and b under a single wheel

Figure $5 b$ shows that when the front and rear axles of the vehicle passed through the sampling point, respectively, the main form of transverse strain under a single wheel was opposite in direction to that of the centerlines of the two wheels at different depths, and transverse compressive strain on top of the pavement was close in value to transverse tensile strain at the bottom of the pavement. At the same time, transverse strains at different distances from the subgrade were far lower than those at different depths of the pavement, and the transverse strain fluctuated between -9 and $10 \mu \varepsilon 1 \mathrm{~m}$ away from the subgrade.

A comparison between Fig. $5 a$, b shows that the transverse strain under a single wheel was about two to four times that at the centerline of the two wheels. The transverse strain at the centerline of the two wheels was significantly affected by the effect of superposition of the wheel, and the difference in it was not significant when the front and rear axles of the vehicle passed through the sampling point, respectively. However, the longitudinal strain under a single wheel was less affected by the effect of superposition of the wheel, and the difference in transverse strain was significant when the front and rear axles passed through the sampling point, respectively.

\section{Three-dimensional strain response analysis under different working conditions}

The 3D strain response of the asphalt pavement is affected by many factors, of which the most important are the parameters of its structural layer. Therefore, the influence of thickness of the pavement, modulus, and equivalent resilient modulus on top of the base on the 3D strain of the asphalt pavement was analyzed. The thickness of the pavement was $0.14-0.38 \mathrm{~m}$, at intervals of $0.04 \mathrm{~m}$. Its modulus was 1000-6000 MPa at intervals of $1000 \mathrm{MPa}$, and the equivalent resilient modulus of the top of the subgrade was $500-5500 \mathrm{MPa}$ at intervals of $1000 \mathrm{MPa}$. Given that the $3 \mathrm{D}$ strain under a single wheel was higher than that at the centerline of two wheels, and was the most unfavorable position for 3D strain response, the vertical compressive strain, longitudinal tensile strain, and transverse tensile strain under a single wheel were selected for subsequent analysis.

\subsection{Analysis of vertical compressive strain response}

Figure 6 shows the influence of the thickness of the pavement, its modulus, and equivalent resilient modulus of the top of the base on vertical compressive strain. The tensile strain was positive and the compressive strain negative. In the figures, $E_{\mathrm{t}}$ is the equivalent resilient modulus of the top of the base and $E_{c}$ is the modulus of the pavement.

According to Fig. $6 \mathrm{a}$, when the equivalent resilient modulus on top of the base was $500 \mathrm{MPa}$ and the thickness of the pavement was constant, the vertical compressive strain decreased with an increase in the modulus of the pavement, and the amplitude decreased gradually. When the modulus of the pavement was constant, the vertical compressive strain decreased with an increase in the thickness of the pavement.

Figure $6 \mathrm{~b}$ shows that when the modulus of the pavement was $2000 \mathrm{MPa}$ and its thickness was constant, the vertical compressive strain decreased with an increase in the equivalent resilient modulus on top of the base. When the latter was higher than $2500 \mathrm{MPa}$, the amplitude of vertical compressive strain decreased sharply. When the modulus of the pavement was constant, the vertical 


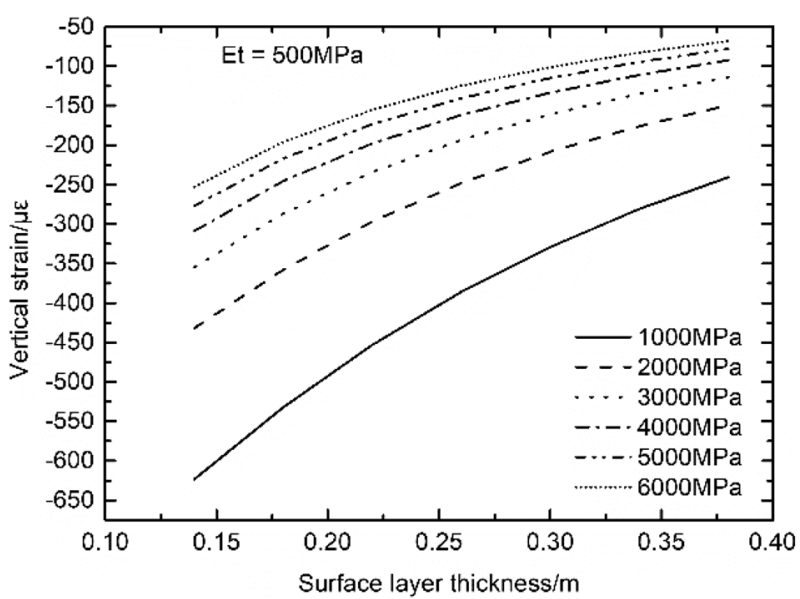

(a)

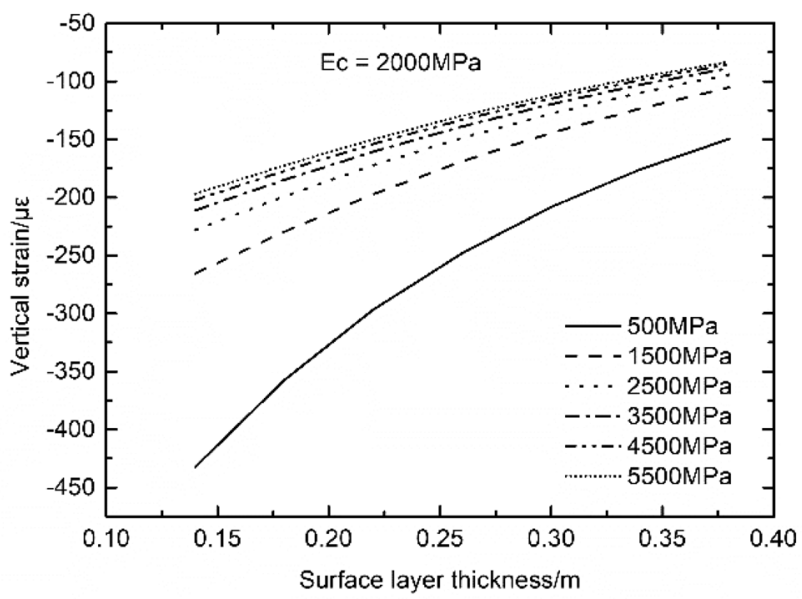

(b)

Fig. 6 Response of vertical compressive strain under the influence of $\mathbf{a}$ the thickness and modulus of the pavement (equivalent resilient modulus on top of the base was $500 \mathrm{MPa}$ ), and $\mathbf{b}$ the thickness of the pavement and equivalent resilient modulus on top of the base (modulus of the pavement was $2000 \mathrm{MPa}$ )

compressive strain decreased with an increase in the thickness of the pavement.

\subsection{Analysis of longitudinal tensile strain response}

Figure 7 shows the influence of the thickness of the pavement, its modulus, and the equivalent resilient modulus on top of the base on longitudinal tensile strain. The tensile strain was positive and the compressive strain negative.

According to Fig. $7 a$, when the equivalent resilient modulus on top of the base was $500 \mathrm{MPa}$ and the thickness of

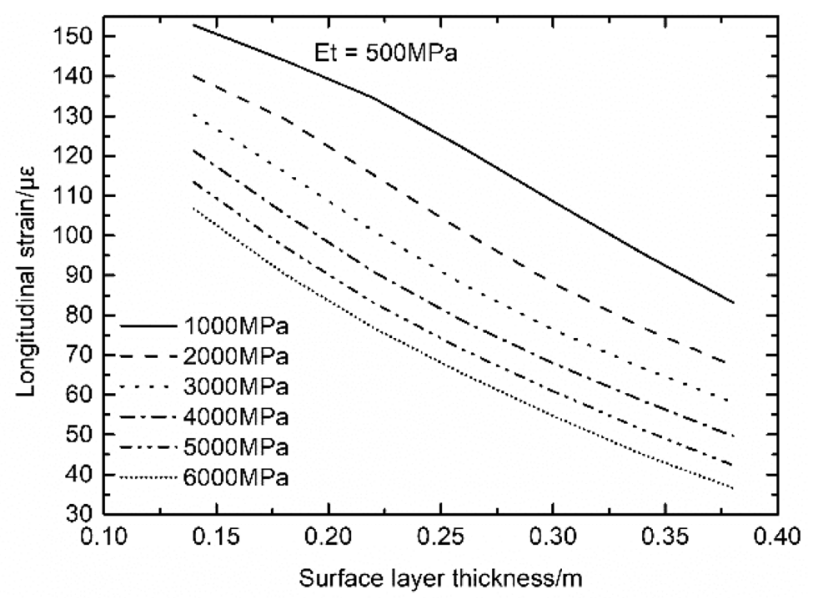

(a)



(b)

Fig. 7 Response of longitudinal tensile strain under the influence of $\mathbf{a}$ the thickness and modulus of the pavement (equivalent resilient modulus on top of the base was $500 \mathrm{MPa}$ ), and $\mathbf{b}$ the thickness of the pavement and the equivalent resilient modulus on top of the base (modulus of the pavement was $2000 \mathrm{MPa}$ )

the pavement was constant, the longitudinal tensile strain decreased with an increase in the modulus of the pavement, and the amplitude decreased gradually. When the modulus of the pavement was constant, the longitudinal tensile strain decreased with an increase in the thickness of the pavement.

Figure $7 \mathrm{~b}$ shows that when the modulus of the pavement was $2000 \mathrm{MPa}$ and its thickness was constant, the longitudinal tensile strain decreased with an increase in the equivalent resilient modulus on top of the base. When the latter exceeded $2500 \mathrm{MPa}$, the amplitude of growth in the longitudinal tensile strain decreased sharply. When the 


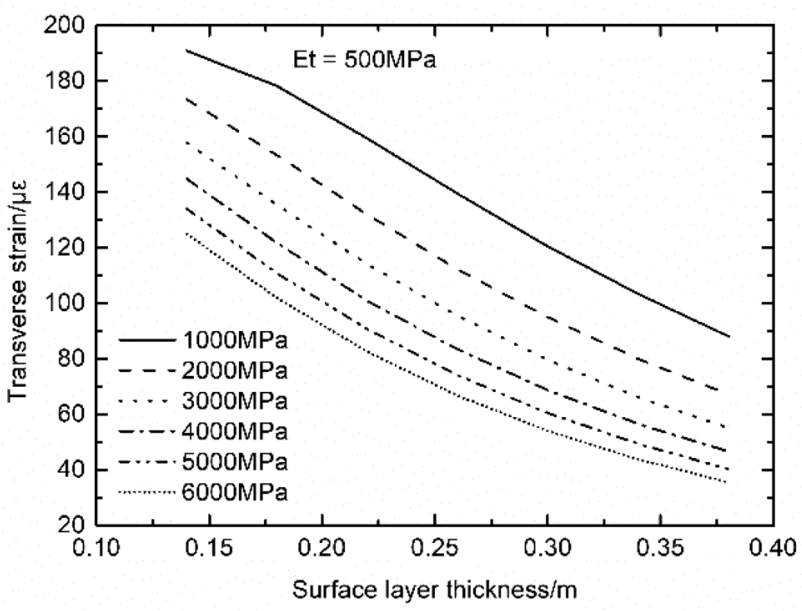

(a)

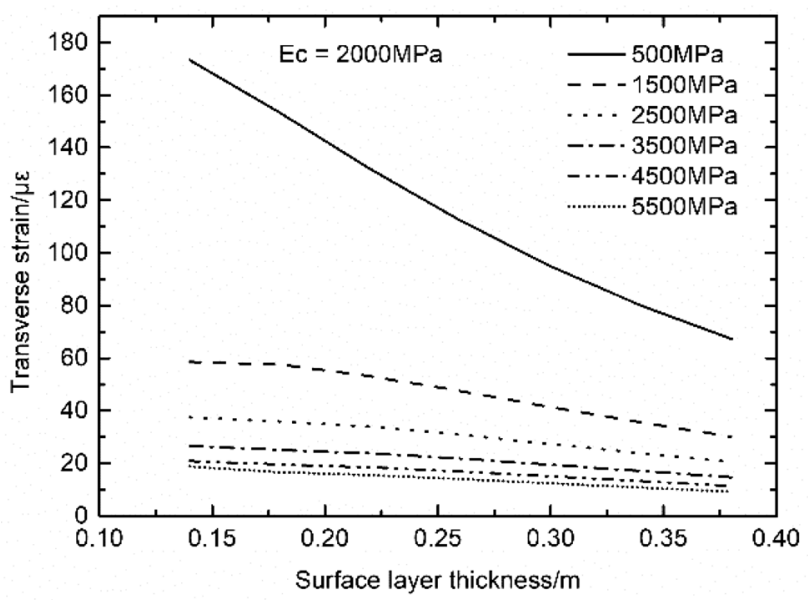

(b)

Fig. 8 Response of transverse tensile strain under the influence of a the thickness of the pavement and its modulus (equivalent resilient modulus on top of the base was $500 \mathrm{MPa}$ ), and $\mathbf{b}$ the thickness of the pavement and the equivalent resilient modulus on top of the base (modulus of the pavement was $2000 \mathrm{MPa}$ )

modulus of the pavement was constant, the longitudinal tensile strain decreased with an increase in the thickness of the pavement.

\subsection{Analysis of transverse tensile strain response}

Figure 8 shows the influence of the thickness of the pavement, its modulus, and the equivalent resilient modulus on top of the base on transverse tensile strain. The tensile strain was positive and the compressive strain negative.

According to Fig. 8a, when the equivalent resilient modulus on top of the base was $500 \mathrm{MPa}$ and the thickness of the pavement was constant, the transverse tensile strain decreased with an increase in the modulus of the pavement, and the decreasing amplitude decreased gradually. When the modulus of the pavement was constant, the transverse tensile strain decreased with an increase in the thickness of the pavement.

Figure $8 \mathrm{~b}$ shows that when the modulus of the pavement was $2000 \mathrm{MPa}$ and its thickness was constant, the transverse tensile strain decreased with an increase in the equivalent resilient modulus on top of the base. When the latter exceeded $2500 \mathrm{MPa}$, the increasing amplitude of transverse tensile strain decreased sharply. When the modulus of the pavement was constant, the transverse tensile strain decreased with an increase in the thickness of the pavement.

A comparison of Figs. 6, 7, 8 shows that the values and range of values of vertical compressive strain were greater than those of longitudinal and transverse tensile strains.

\section{Three-dimensional strain analysis model}

The above analysis shows that 3D strain at the bottom of the asphalt pavement was related to its thickness, modulus, and the equivalent resilient modulus on top of the base under a constant vehicle load and traffic speed. Therefore, a 3D model to predict strain in the asphalt pavement was established using the parameters. It was used to predict the 3D strain at the bottom of the asphalt pavement to evaluate its structural performance using data from nondestructive road testing. Based on 252 sets of combinations of road structure, models to predict the vertical compressive strain, longitudinal tensile strain, and transverse tensile strain were established as below. $h_{c}$ is the thickness of the pavement.

Vertical compressive strain, $500 \leq E_{t}<1500 \mathrm{MPa}$ :

$$
\begin{aligned}
\varepsilon_{Z}= & {\left[\left(-2 \times 10^{-6} E_{t}^{2}+0.017 E_{t}-118.2\right) \ln \left(E_{c}\right)+\left(3 \times 10^{-5} E_{t}^{2}-0.2264 E_{t}+1233\right)\right] } \\
& \times \ln \left(h_{c}\right)+\left(-0.0022 E_{t}-7.7368\right) \ln \left(E_{c}\right)+\left(5 \times 10^{-6} E_{t}^{2}-0.037 E_{t}+215.76\right)
\end{aligned}
$$

Vertical compressive strain, $1500 \leq E_{t} \leq 5500 \mathrm{MPa}$ :

$$
\begin{aligned}
\varepsilon_{Z}= & {\left[\left(-0.0012 E_{t}-83.94\right) \ln \left(E_{c}\right)+\left(2 \times 10^{-6} E_{t}^{2}-0.0173 E_{t}+847.05\right)\right] \ln \left(h_{c}\right) } \\
& +\left(-8.832 \ln \left(E_{t}\right)+56.387\right) \ln \left(E_{c}\right)+\left(49.063 \ln \left(E_{t}\right)-245.27\right)
\end{aligned}
$$


Longitudinal tensile strain, $500 \leq E_{t}<1500 \mathrm{MPa}$ :

$$
\begin{aligned}
\varepsilon_{X}= & {\left[\left(2 \times 10^{-6} E_{t}-0.0089\right) E_{c}+\left(125.89 \ln \left(E_{t}\right)-1073.8\right)\right] h_{c} } \\
& +\left(-0.0016 \ln \left(E_{t}\right)+0.4515\right) \ln \left(E_{c}\right)+\left(1 \times 10^{-5} E_{t}^{2}-0.0985 E_{t}+232.99\right)
\end{aligned}
$$

Longitudinal tensile strain, $1500 \leq E_{t} \leq 5500 \mathrm{MPa}$ :

$$
\begin{aligned}
\varepsilon_{X}= & {\left[\left(0.0074 \ln \left(E_{t}\right)-0.0604\right) E_{c}+\left(-5 \times 10^{-6} E_{t}^{2}+0.044 E_{t}-121.27\right)\right] h_{c} } \\
& +\left(-4.433 \ln \left(E_{t}\right)+30.66\right) \ln \left(E_{c}\right)+\left(4 \times 10^{-6} E_{t}^{2}-0.0257 E_{t}+109.72\right)
\end{aligned}
$$

Transverse tensile strain, $500 \leq E_{t} \leq 1500 \mathrm{MPa}$ :

$$
\begin{aligned}
\varepsilon_{Y}= & {\left[\left(2 \times 10^{-6} E_{t}-0.0085\right) E_{c}+\left(177.69 \ln \left(E_{t}\right)-1507.1\right)\right] h_{c}+} \\
& \left(6 \times 10^{-7} \ln \left(E_{t}\right)-4 \times 10^{-6}\right) E_{c}^{2}+\left(-3 \times 10^{-9} E_{t}^{2}+2 \times 10^{-5} E_{t}-0.0297\right) E_{c}+53957 E_{t}^{-0.854}
\end{aligned}
$$

Transverse tensile strain, $1500<E_{t} \leq 5500 \mathrm{MPa}$ :

$$
\begin{aligned}
\varepsilon_{Y}= & {\left[\left(1 \times 10^{-6} E_{t}-0.0094\right) E_{c}+\left(-8 \times 10^{-6} E_{t}^{2}+0.0732 E_{t}-201.44\right)\right] h_{c}+} \\
& \left(1 \times 10^{-6} \ln \left(E_{t}\right)-8 \times 10^{-6}\right) E_{c}^{2}+\left(-3 \times 10^{-6} E_{t}+0.0067\right) E_{c}+\left(4 \times 10^{-6} E_{t}^{2}-0.0382 E_{t}+126.14\right)
\end{aligned}
$$

\section{Conclusions}

This study analyzed a 3D strain-induced dynamic response model of a pavement based on a model of a vehicle and one of a road. The following conclusions can be drawn:

(1) The vertical, longitudinal, and transverse strains of the centerline of two wheels and a single wheel were alternating. However, the 3D strain at the centerline of the two wheels was affected by the effect of superposition of the wheel, and the difference in the values of 3D strain were not prominent when the front and rear axles of the vehicle passed through the sampling point, respectively. The 3D strain under a single wheel was more prominent when the front and rear axles of the vehicle passed through the sampling point. The 3D strain under a single wheel was about two to five times that at the centerline of two wheels, and was the most unfavorable location of the road structure.

(2) The vertical strain under a single wheel was mainly compressive strain at different depths of the road structure, and compressive strain at the bottom of the pavement was slightly higher than that on top of it. The longitudinal strain and transverse strain under a single wheel was mainly compressive strain on top of the pavement and tensile strain at its bottom. The values of longitudinal and transverse strains on the top and bottom of the pavement were similar.
(3) The vertical, longitudinal, and transverse strains under a single wheel decreased with an increase in the distance from the subgrade. When the distance from the subgrade was $1 \mathrm{~m}$, the 3D strain tended to be stable and fluctuated in a small range.

(4) The 3D strain under a single wheel decreased with an increase in the thickness of the pavement, its modulus, and the equivalent resilient modulus on top of the base. The influence of the latter on the 3D strain was the most significant. When it exceeded $2500 \mathrm{MPa}$, the 3D strain decreased sharply.

(5) Based on 252 sets of combinations of road structures, models to predict the vertical compressive strain, longitudinal tensile strain, and transverse tensile strain were established. They can provide a reference for the detection and evaluation of asphalt pavements. However, these models have yet to be verified by field tests. The authors plan to undertake this work in a future study.

Acknowledgements This work was supported in part by the National Natural Science Foundation of China (No. 52108333), and the Open Fund Projects of Civil Airport Engineering Research Base of China (No.2020003).

Author contributions Dr. ZR designed the study, interpreted the results and wrote the manuscript. Dr. LX complied the models, conducted the analysis. Prof. ZX contributed to the discussion and background of the study. All authors commented on the manuscript and approved the submission. 


\section{Declarations}

Conflict of interest The authors declare no competing interests.

Open Access This article is licensed under a Creative Commons Attribution 4.0 International License, which permits use, sharing, adaptation, distribution and reproduction in any medium or format, as long as you give appropriate credit to the original author(s) and the source, provide a link to the Creative Commons licence, and indicate if changes were made. The images or other third party material in this article are included in the article's Creative Commons licence, unless indicated otherwise in a credit line to the material. If material is not included in the article's Creative Commons licence and your intended use is not permitted by statutory regulation or exceeds the permitted use, you will need to obtain permission directly from the copyright holder. To view a copy of this licence, visit http://creativecommons. org/licenses/by/4.0/.

\section{References}

1. Olidid C, Hein D (2004) Guide for the mechanistic-empirical design of new and rehabilitated pavement structures, NCHRP 1-37A Final Report. ARA, Inc, ERES Consultants Division

2. Jtg D50-2017 (2017) Specifications of asphalt pavement design for highway. Beijing: China Communications Press, (in Chinese)

3. Yu X, Tan Z (2012) Approximate calculation of flexural stress and tensile strains in asphalt pavements. J Tongji Univ (Nat Sci) 40(6):849-853 (in Chinese)

4. Dong Z, Tan Y (2015) Dynamic response of asphalt pavement. Science Press, Beijing (in Chinese)

5. Yan K, Xu H, You L (2016) Analytical layer-element approach for wave propagation of transversely isotropic pavement. Int J Pavement Eng 17(3):275-282

6. Arraigada M, Pugliessi A, Partl MN et al (2014) Effect of fullsize and down-scaled accelerated traffic loading on pavement behavior. Mater Struct 47(8):1409-1424

7. Xiao C, Qiu Y, Ai C et al (2016) Experiment on dynamical characteristics of asphalt pavement under vehicle load. J Chang'an Univ (Nat Sci Edi) 36(2):26-34 (in Chinese)

8. Khattak M, Mohammad L, Yuan F et al (2012) Variability of insitu HMA volumetric and mechanistic characteristics using non-destructive test (NDT): case study. Int J Pavement Eng 13(2):110-125

9. Tarefder RA, Islam MR (2015) Study and evaluation of materials response in hot mix asphalt based on field instrumentation phase I: Final report NM11MSC-03. University of New Mexico

10. Ahmed MU, Rahman A, Islam MR et al (2015) Combined effect of asphalt concrete cross-anisotropy and temperature variation on pavement stress-strain under dynamic loading. Constr Build Mater 93:685-694

11. Norouzi A, Kim D, Kim YR (2016) Numerical evaluation of pavement design parameters for the fatigue cracking and rutting performance of asphalt pavements. Mater Struct 49(9):3619-3634

12. Li MY, Wang H, Xu GJ et al (2017) Finite element modeling and parametric analysis of viscoelastic and nonlinear pavement responses under dynamic FWD loading. Constr Build Mater 141(2):23-35
13. Wang $\mathrm{H}$, Ai-Qadi IL (2011) Impact quantification of wide-base tire loading on secondary road flexible pavements. J Transp Eng 137(9):630-639

14. Ozer H, Al-Qadi IL, Wang $\mathrm{H}$ et al (2012) Characterization of interface bonding between hot-mix asphalt overlay and concrete pavements: modelling and in-situ response to accelerated loading. Int J Pavement Eng 13(2):181-196

15. Chen J, Wang H, Li M et al (2016) Evaluation of pavement responses and performance with thermal modified asphalt mixture. Mater Des 111:88-97

16. Wang H, Li MY (2016) Comparative study of asphalt pavement responses under FWD and moving vehicular loading. J Transp Eng. https://doi.org/10.1061/(ASCE)TE.1943-5436.0000902

17. Dong Z, Cao L, Tan Y et al (2009) Analysis of the dynamic response of three directional strains in asphalt pavement under moving vehicle loads. Chin Civil Eng J 42(4):133-139 (in Chinese)

18. Chen Y, Dai Z, Chen $\mathrm{H}$ et al (2016) Strain analysis of a flexible asphalt pavement under muli-wheel random dynamic loads of vehicles. J Vibration Shock 35(19):15-19 (in Chinese)

19. Pan Q, Zheng J, Yang B et al (2017) Field prediction method and experiment on creep response of asphalt pavement. China J Highw Transp 30(9):10-17 (in Chinese)

20. Yuejing LV, Wei C, Ying B et al (2017) Mechanical responses of asphalt pavement under half-sine load. J Wuhan Univ Sci Technol (Nat Sci Edit) 40(6):457-463 (in Chinese)

21. Wang $\mathrm{H}$, Zhao J, Hu X et al (2020) Flexible pavement response analysis under dynamic loading at different vehicle speeds and pavement surface roughness conditions. J Transp Eng 146(3):1-26

22. Zhao J, Wang H (2020) Dynamic pavement response analysis under moving truck loads with random amplitudes. J Transp Eng 146(2):04020020

23. Ye Z, Miao Y, Zhang W et al (2021) Effects of random non-uniform load on asphalt pavement dynamic response. Int J Pavement Res Technol 14(3):299-308

24. Wang S-P, Dan H-C, Li L et al (2021) Dynamic response of asphalt pavement under vibration rolling load: theory and calibration. Soil Dyn Earthq Eng 143:106633

25. Wen J (2014) Dynamic response analysis and performance prediction of Jilin perpetual asphalt pavement. Harbin Institute of Technology, (in Chinese)

26. Ou C (2005) Dynamic response analysis of asphalt pavement structure. Master thesis of Zhejiang University. (in Chinese)

27. Wang Y (2014) Research on the bridges mechanics performance under the standard energy impact load. Civil Aviation University of China, (in Chinese)

28. Liang H (2013) Analysis of time-history responses of layered asphalt pavement structure under moving load. Master thesis of Central South University. (in Chinese)

29. Huang Q, Ling J (2011) Methodology study on defining subgrade's working area. J Tongji Univ (Nat Sci) 39(4):551-555 (in Chinese)

30. Lv P, Dong Z (2010) Mechanical analysis of vehicle -asphalt pavement system. China Communications Press, Beijing (in Chinese)

Publisher's Note Springer Nature remains neutral with regard to jurisdictional claims in published maps and institutional affiliations. 